\title{
Successful endoscopic polypectomy for colonic vascular ectasia presenting as pedunculated polypoid lesion
}

Colonic vascular ectasia is a potential and frequent cause of lower intestinal bleeding in the elderly. Recent advances in colonoscopy have discovered colonic vascular ectasia with increasing frequency. Colonic vascular ectasia often presents as multiple reddish, slightly elevated, mucosal lesions. It may be treated at colonoscopy with laser photocoagulation, heat probe, electrocoagulation, and argon plasma coagulation [1-4]. We present a case of an unusual pedunculated polypoid colonic ectasia that was successfully treated with endoscopic polypectomy.

A healthy 69-year-old man underwent colonoscopy because of recent anal discomfort and frequent abdominal fullness. Laboratory tests did not reveal anemia or positive fecal blood test. Colonoscopy revealed a soft, reddish pedunculated polypoid lesion, about $2.5 \mathrm{~cm}$ in diameter, with superficial ulceration and some bloody exudates at the ascending colon. Endoscopic polypectomy for suspected malignancy was carried out without complication ( $\bullet$ Fig. 1). Histopathologic evaluation of the resection specimen showed edematous submucosa with an obvious dilated vein lined by endothelial cells. Some dilated capillaries were also found in the mucosa ( Fig. 2). Colonic vascular ectasia was diagnosed. At 1-year follow-up, the patient was uneventful.

The typical endoscopic appearance of colonic vascular ectasia was often reported to be a slightly elevated reddish mucosal lesion. Pedunculated polypoid morphology of colonic vascular ectasia is extremely rare. This case suggests that colonic vascular ectasia could present as a single, asymptomatic, pedunculated lesion with an ulcerative surface. Furthermore, the lesion can be safely removed by endoscopic polypectomy with electrocoagulation snare.

Endoscopy_UCTN_Code_CCL_1AD_2AC
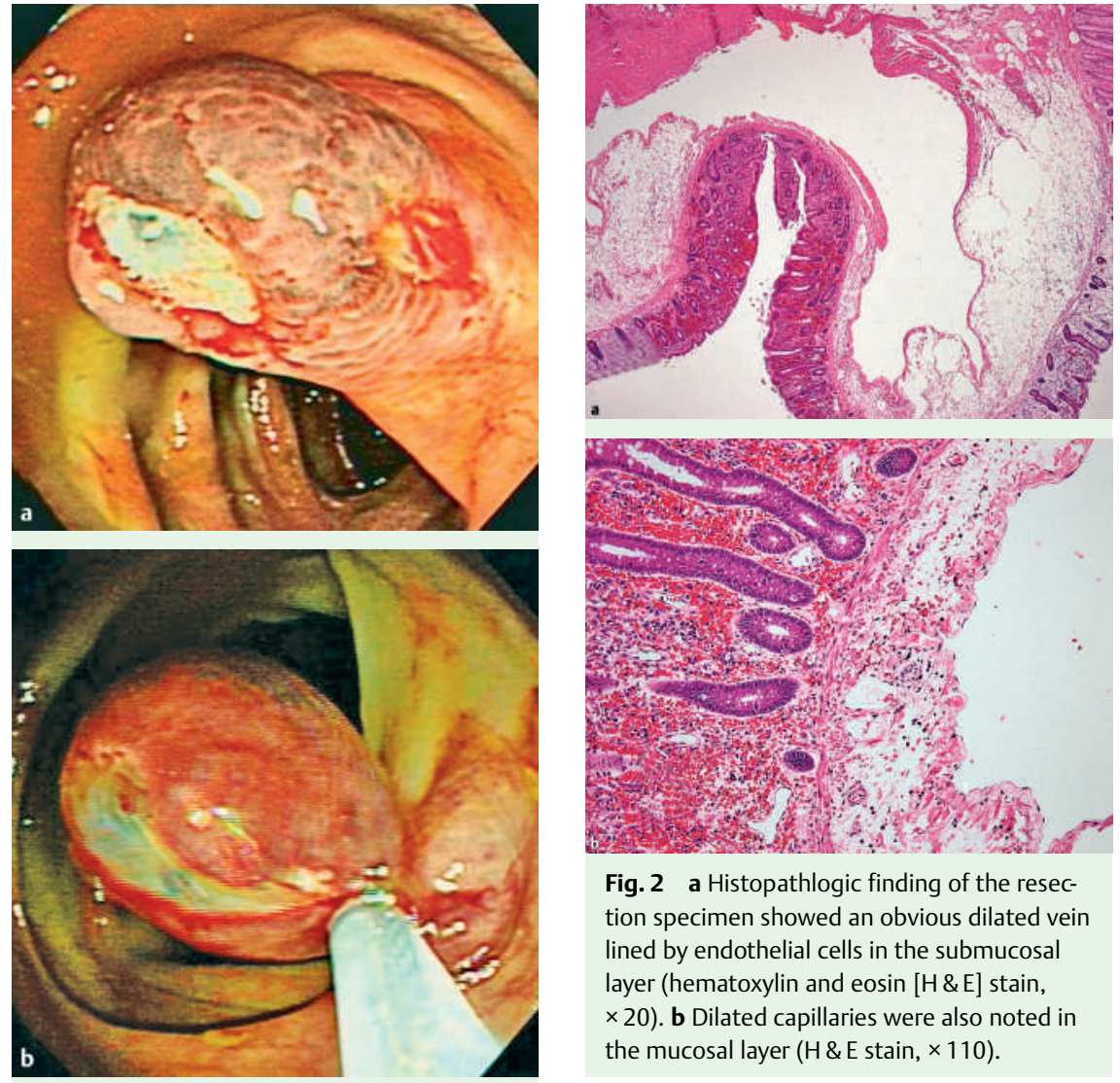

Fig. 2 a Histopathlogic finding of the resection specimen showed an obvious dilated vein lined by endothelial cells in the submucosal layer (hematoxylin and eosin [H \& E] stain, $\times 20$ ). $\mathbf{b}$ Dilated capillaries were also noted in the mucosal layer ( $\mathrm{H} \& \mathrm{E}$ stain, $\times 110)$.

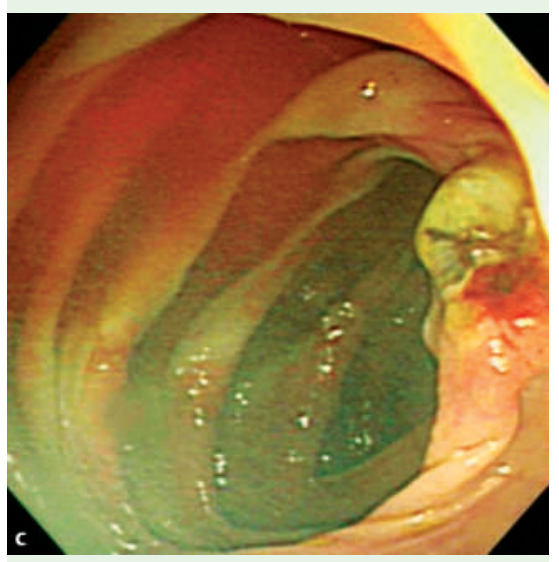

Fig. 1 Colonoscopy revealed a reddish pedunculated polypoid lesion about $2.5 \mathrm{~cm}$ in size, with an ulcerative surface and bloody exudates (a). b The polypoid lesion was snared by an electrocoagulation device. c Polypectomy was carried out without immediate complication.
I. T. Lin ${ }^{1}$, W. H. Chang ${ }^{1,4}$, S. C. Shih ${ }^{1,4}$, S. C. Lin ${ }^{1}$, Y. J. Chen ${ }^{3}$, H. Y. Wang ${ }^{1}$, C. H. Chu ${ }^{1,4}$, T. E. Wang ${ }^{1,4}$, T. C. Liou ${ }^{1,4}$, L. R. Shyung ${ }^{1}$, M. J. Bair ${ }^{2}$

Division of Gastroenterology, Department of Internal Medicine, Mackay Memorial Hospital, Taipei, Taiwan

2 Division of Gastroenterology, Taitung branch of Mackay Memorial Hospital, Taitung, Taiwan

3 Department of Pathology, Mackay Memorial Hospital, Taipei, Taiwan

${ }^{4}$ Mackay Medicine, Nursing and Management College, Taipei, Taiwan Department of Internal Medicine, 


\section{References}

1 Tada Y, Okamura S, Okita Yet al. Vascular ectasia of the colon treated by argon plasma coagulation: report of a case. Dig Endosc 2001; 13: 37-40

2 Kakushima N, Fujishiro M, Yahagi $N$ et al. An unusual case of polypoid angiodysplasia. Endoscopy 2004; 36: 379

$3 \mathrm{Fu}$ KI, Fujimori T. Bleeding angiodysplasia in the duodenum. $\mathrm{N}$ Engl J Med 2006; 354: 283

4 da Silva LE, Borros MS, Tafner E et al. Endoscopy treatment of colon vascular ectasia during bleeding with injection of adrenaline solution at $1: 10000$ and monopolar electrocoagulation: an alternative approach. Arq Gastroenterol 1995; 32: 31 - 34
Bibliography

DOI 10.1055/s-2007-966407

Endoscopy 2007; 39: 253-254

(C) Georg Thieme Verlag KG Stuttgart · New York .

ISSN 0013-726X

\section{Corresponding author}

\section{J. Bair, MD}

Division of Gastroenterology

Department of Internal Medicine

Taitung branch of Mackay Memorial Hospital

1 Lane 303

Changsha Street

Taitung

Taiwan

Fax: +886-89-321240

a5963@ttms.mmh.org.tw 